BMJ Open Ophthalmology

\section{Sex, gender and blindness: a new framework for equity}

To cite: Doyal L,

Das-Bhaumik RG. Sex, gender and blindness: a new framework for equity. BMJ Open Ophthalmology 2018;3:e000135. doi:10.1136/ bmjophth-2017-000135

Received 28 November 2017 Revised 6 March 2018 Accepted 16 March 2018
Check for updates

(C) Author(s) (or their employer(s)) 2018. Re-use permitted under CC BY-NC. No commercial re-use. See rights and permissions. Published by BMJ.

${ }^{1}$ University of Bristol, Bristol, UK ${ }^{2}$ Moorfields Eye Hospital,

London, UK

${ }^{3} \mathrm{UCL}$ Institute of Ophthalmology, London, UK

Correspondence to Professor Lesley Doyal; I.doyal@ bristol.ac.uk

\section{ABSTRACT}

Four-fifths of all blind or vision impaired people live in middle-income and low-income countries with the African region and parts of Asia and the Middle East bearing the heaviest burden. At the same time, we know that around two thirds of all blind people in the world are female. Hence, the poorest (and usually the oldest) women are most likely to have their lives limited by visual impairment. While recent strategies have focussed on international variations in eye health, very few have paid attention to the gender differences that are an inextricable element in these inequalities. This review will explore possible explanations for the advantage of men in the exercise of one of the most basic of human senses. It will show that this cannot be understood through the use of a biomedical approach alone. Broader social perspectives will also be needed in order to create an appropriate knowledge base for tackling global inequalities in blindness.

\section{MEN, WOMEN AND BLINDNESS}

Very few researchers have attempted a formal comparison of the eye health of women and men. Many studies have been carried out either on all male samples or on mixed groups where findings from male and female subjects are not analysed separately. But it is clear that vision disorders do affect women disproportionately. ${ }^{1-3}$ A recent report on gender inequities in health problems indicated that five of the six eye conditions listed had a female to male excess of 1.2 or more This ratio holds true (although for different reasons) for virtually all the preventable and treatable blinding conditions in the world, including cataract and trachoma in particular. Prevalence only reaches equality in less common diseases such as age-related macular degeneration.

Cataracts dominate all causes of blindness and visual impairment around the world, and it is clear that women are more likely than men to develop them. A recent global survey estimated that two-thirds of all cataract blindness was in women. ${ }^{5}$ However, ratios vary in different settings. One study in Pakistan, for example, found that the prevalence of cataract blindness was twice as high among women as among men. ${ }^{6}$ Evidence from epidemiological studies suggests that biological sex differences play a significant part in this excess of cataracts among women but the mechanisms behind this are not yet clear.

The second major example of inequities in vision between women and men is trachoma which is still endemic in more than 50 countries. Over time, repeated infections result in the development of scar tissue on the inside of the eyelid. This may eventually lead to trichiasis, from a resultant entropion, eventually leading to corneal abrasion, ulceration, perforation and ultimately the loss of sight.

Girls and women are infected with trachoma between two and four times more frequently than boys and men at all ages. They are also nearly twice as likely as men to develop the more serious trichiasis which results from repeated episodes of infection. ${ }^{8}$ About 80-85 million women are estimated to have active trachoma; 8 million to have trichiasis and 3 million to be blind from the infection. ${ }^{7 \mathrm{i}}$ In this case, however, there is little or no evidence of a sex-linked predisposition for trachoma. Hence, the excess risk they bear throughout their lives suggests that unlike cataracts, social factors rather than biology are likely to be mainly responsible.

Around three-quarters of vision problems are either preventable or correctable so that variations between women and men are not 'natural' and unavoidable. Instead, they reflect a combination of inherent biological vulnerabilities and socially constructed inequities that need urgent attention if women and men in different parts of the world are to realise their potential for eye health.

\section{SEX AND GENDER: THE WIDER DEBATE}

Most of the differences between the health of women and men have traditionally been framed by medical researchers within the language of biology, with sex differences in reproductive systems as the focal point of differentiation. ${ }^{9}$ However, the last decade in

${ }^{\mathrm{i}}$ There may be many more cases because relatively few individuals are routinely examined. According to the Global Alliance for Women's Health the real figure could be a multiple of 10 times or more. ${ }^{20}$ 
particular has seen a shift towards what has been referred to as a 'social determinants of health' approach. ${ }^{10}$ This emphasises the fact that patterns of health and illness reflect not just biological variables but also a wide range of external influences.

A major part of this reconceptualisation has been a recognition that differences between the daily lives and physical circumstances of women and men (including access to effective healthcare) will play a significant part in shaping inequalities in their respective experiences of health and illness. As part of this refocussing, the concept of 'gender difference' has increasingly been used by researchers alongside that of the more traditional 'sex difference'. This is potentially an important step forward in recognising the distinction between social and biological domains.

But too often these terms continue to be used interchangeably on the assumption that 'gender' is simply a more modern or even 'politically correct' word for 'sex'. In reality, however, this changing terminology is more than a mere semantic shift. Sex is still the appropriate term for describing those differences which are biological in origin, deriving from an individual's chromosomes. Gender on the other hand refers to the differences in social, economic and cultural resources allocated to male and female individuals. As recent debates have shown, it is often a combination of influences from both these arenas that shape variations in health between women and men across a range of settings. ${ }^{11-13}$

The last decade has seen a growing body of research exploring the relationships between the biological and the social in a number of medical fields. The USA has been at the centre of this work with protocols increasingly being required by funders to reflect this methodological shift. Research on coronary heart disease and HIV, for example, have both provided important illustrations of the added value of this more integrated approach. ${ }^{\text {ii }}$ But much less has been done to explore these issues in some of the smaller medical specialties such as ophthalmology. ${ }^{\text {iii }}$ One starting point to remedy this deficit would be the development of more studies focussing on either men or women in different age cohorts. But most importantly it will be essential that all research designs take the potential significance of sex and gender into account in framing the questions to be explored, in calculating sample size to include adequate sub samples and in

\footnotetext{
${ }^{\text {ii }}$ For an extensive discussion of these issues and an overview of related methodological issues, see recent documents from the US Office of Women's Health (http://orwh.od.nih.gov/ resources/cme.asp).

iii The marked exception to this generalisation is a group of Canadian and US ophthamologists who have led the way in developing both gender sensitive research as well as projects directed at older women in particular. These include Paul Courtright and Susan Lewallan of the Kilimanjaro Centre for Community Ophthamology. Similar points can be made about dentistry see Doyal and Naidoo 2010. ${ }^{37}$
}

analysing any differences detected between women and men.

\section{HOW SHOULD WE EXPLAIN INEQUALITIES IN VISION BETWEEN WOMEN AND MEN?}

At first glance, we might assume that it is differences in life expectancy that are the major factors explaining men's advantage. Most major eye problems are associated with ageing and women now live longer than men in most parts of the world. Hence, more of them are likely to survive to develop vision problems. However, this is certainly not the only explanation since women are more affected than men by most eye diseases at all ages. They also appear to receive less effective and appropriate eye care than men. We therefore need to look at the social as well as the biological factors that put females at greater risk of visual impairment and ultimately blindness.

\section{Biological perspectives on sex differences in blindness}

Sex differences in biology have traditionally been used to explain inequalities in blindness. Within a biomedical model, these physiological differences have generally been assumed to fall into two categories: those related to hormonal aspects of reproductive systems and those derived from differential functioning of male and female immune systems. But so far, there has been little research on precisely how these biological factors operate (either separately or together) in the aetiology of eye diseases. ${ }^{14 \mathrm{iv}}$

A relatively small number of studies have explored the potential role of oestrogen levels in creating the female excess of lens opacities. ${ }^{5}$ It would appear, for example, that oestrogen plays a protective role in preventing the oxidation of the lens that can lead to the formation of cataracts, thus explaining the higher rates in postmenopausal women as their levels of the hormone are declining. Similarly, there appears to be a link between female hormones and dry eye. This condition is twice as common among women as among men and appears to be triggered by the menopause and other causes of early ovarian insufficiency. ${ }^{15-17}$

For some women, the hormonal changes associated with pregnancy may also lead to blurred vision as well as being an early sign of pre-eclampsia. These conditions have been linked with fluid retention but again there has been very little research exploring how this might work. Hence, further studies are urgently needed to establish the exact mechanism by which hormonal changes may affect women's vision over the life cycle.

At the same time, more work is needed to make sense of how differences in male and female immune systems can affect eye health.

The eye is affected by a number of autoimmune conditions. These include, rheumatoid arthritis, Graves' disease, Sjögren's syndrome, systemic lupus erythematosus and

\footnotetext{
${ }^{\text {iv }}$ For a summary of the most recent research evidence on the biological influences on a range of ophthalmic disorders, see special issue of Current Eye Research 2015. ${ }^{3}$
} 
multiple sclerosis—can all be associated with serious eye symptoms.

Autoimmune eye disease prevalence rates range from less than 5 per 100000 , for example, in uveitis, to more than 500 per 100000 as in Graves' disease. At least $85 \%$ of patients with thyroiditis, systemic sclerosis, systemic lupus erythematosus and Sjögren's syndrome are female. ${ }^{18}$ Taken together, autoimmune diseases strike women three times more often than men and some have an even greater excess among women. Specifically, Graves' disease is seven times more common in women and Sjögren's syndrome, nine times more so. ${ }^{19}$ Despite these statistics, they remain among the least understood and poorly recognised of any category of illness. We know that many conditions and syndromes have an underlying autoimmune component, but incomplete understanding of the complex physiology, pathology and symptomatology of immunity, and of autoimmunity in particular leads to great difficulty in further progress in disease detection and management.

It is clear therefore that some of the greater burden of blindness experienced by women can be explained by biological sex differences but that more research is needed to make sense of how they operate. Just as importantly, however, the picture will need to be filled out through looking at the impact of social or gender differences that can also damage or promote eye health. ${ }^{\mathrm{v}}$

\section{Social perspectives on gender differences in blindness}

The most frequently cited example of gender-related environmental causes of eye problems occurs in the context of trachoma. There is little evidence of greater biological susceptibility to this infectious disease among females. Hence, it is widely assumed that the higher rates of trachoma and trichiasis found in women and girls reflect the wider circumstances of their lives and especially the gender division of labour.

The major factor linked to women's vulnerability to trachoma is their greater responsibility for childcare and other hygiene-related tasks. ${ }^{20}{ }^{21}$ In trachoma-endemic areas, it is children who constitute the main reservoir of ocular chlamydia. It is then spread through direct personal contact, shared sleeping spaces, towels and clothes as well as exposure to flies that carry the bacteria from ocular and nasal discharge. Lack of easy access to clean water will naturally exacerbate these problems as will the harm caused by cooking on unventilated stoves in small spaces. As in the case of cataracts, the resulting visual impairment and blindness will inevitably affect women's capacity to carry out the tasks expected of them, but it is important to look beyond the effects of vision impairment itself.

\footnotetext{
${ }^{\mathrm{v}}$ While the focus in this paper is on the impact of gender on women, it is important to note that men too will be affected by gendered dimensions of their lives. In the case of onchocerciasis or river blindness, for example, they are more likely to be infected as a result of their role in water-based agriculture.
}

A recent investigation carried out in a rural village in Niger has given one of the first accounts of the quality of life of those women affected by trichiasis, one of whom described it as 'a living death'. ${ }^{22}$ Most medical accounts have focused on limited visual acuity but women themselves frequently put much greater emphasis on pain and itching 'as if someone's pricking my eye with a thorn'. ${ }^{22}$

Because of the pain and photophobia they experienced, farming was often very difficult. Hence, many described a major decline in their independence and for those without supportive families, financial survival could be very precarious especially if drugs had to be purchased. ${ }^{23}$ This was especially difficult in light of the fact that they were often rejected as future brides or were abandoned by existing husbands. There was evidence of increased stigma and many reported being embarrassed by their weeping and infected eyes. Others were criticised by neighbours for being 'dirty' and for not keeping their houses clean. ${ }^{22} 24$ Thus, the blindness experienced by so many deprived women will have wide-ranging effects not only on them but also on other family members.

Older women in particular are very often the poorest group in a community, and this is exacerbated in the many societies where they are granted especially low status. Hence, inequalities in visual impairment and blindness are biological or social or a combination of both, it is clear that they could be reduced through greater sex and gender sensitivity in related services as well as wider social change. Though women are much more likely than men to develop cataracts they are significantly less likely to receive the surgical intervention that can restore their vision. This inherent inequality in service delivery is not quite so dramatic with trachoma but as we shall see there is still evidence of discrimination that could be remedied with more appropriate policies.

\section{OBSTACLES TO GENDER SENSITIVITY IN EYE CARE SERVICES}

Over the last decade a range of studies have explored the differential use made by women and men of a range of health services. The general conclusion seems to be that even when their reproductive care is excluded, women use services more than men. ${ }^{25}$ In recent years, this has been demonstrated with particular clarity in the context of HIV with men significantly less likely than women to obtain antiretroviral drugs. ${ }^{26 \mathrm{vi}}$ It is striking, therefore, that the pattern seems to be reversed in the context of eye care in those areas where the burden of blindness is most severe.

The adequacy of eye care varies between rich and poor settings and it is in the low-income countries of Africa and Asia that the lack of effective services is most common. ${ }^{27}$ This is true for both women and men but especially for women. Services can of course be either preventive or curative depending on the condition in

\footnotetext{
vi There is now an extensive literature linking men's reluctance to use healthcare to ideas of masculinity and reluctance to reveal weakness. ${ }^{38}$
} 
question. The sex-differentiated biological origins of cataract mean that prevention is not possible. However, surgery can be extremely effective in improving or totally restoring vision. In the case of trachoma on the other hand, prevention is possible through a range of social, economic and cultural strategies. And in the absence of prevention, treatment can include both antimicrobial drugs (annual doses of azithromycin) and surgery. Yet, despite these potentially effective interventions, gender inequalities in blindness remain largely unresolved.

A recent study of 23 low-income and middle-income countries found that men in need of cataract surgery were 1.71 times more likely to get it than women in the same degree of need. ${ }^{28}$ Because women have a higher incidence of cataract and tend to have longer life expectancy than men, equity prescribes that they should account for 60-65 per cent of all cataract operations. Indeed, a recent estimate suggested that if women's access to cataract surgery was equal to that of men, the overall incidence of global blindness would decrease by $12.5 \%{ }^{6}$

In the case of trachoma, SAFE is the main strategy used to attack the disease through both prevention and treatment. ${ }^{\text {vii }}$ An essential element in this programme is education for women (and men) about the importance of face washing and other hygiene measures. This in turn will require significant environmental improvements particularly easy access to clean water and sanitation. Those who are already infected can usually be helped with a combination of drugs and sometimes surgery. ${ }^{29}$ But again, there is clear evidence of inequality and discrimination in service delivery and too little emphasis on gender in evaluation. A number of studies have shown, for example, that women are more likely than men to have recurrence of trichiasis after surgery. ${ }^{7}$ This can have several causes including the fact that women often have to wait longer for surgery until the trichiasis is more severe.

Any attempt to understand these gaps between need and use of services must begin with a wider perspective on gender divisions across a range of settings. There is now a vast literature highlighting the inequalities that exist in income, power and status between women and men. Though these vary in form and intensity between communities, there are obvious similarities that play a key role in limiting women's access to eye care. Central to these inequalities is women's limited influence over decision-making in both community and national settings. Hence, they are unlikely to be able to exert pressure for improving the provision of infrastructure.

Women are also likely to have access to fewer resources than men. ${ }^{30}$ Hence, the way that eye care if funded will have important gender implications. This is especially important in the context of household budgets where

\footnotetext{
vii SAFE, surgery, antibiotics, (cure) face washing, environmental change (prevention).
}

scarce resources are more likely to be used for the benefit of boys and men and women will have little power to alter such decisions. ${ }^{28} 3132$ Even if resources are available, women may be hindered by the limitations on their freedom to travel without an escort and the need to find alternative carers for those for whom they are normally responsible.

Women's use of services may also be limited by their own lack of knowledge especially given the high rates of illiteracy among those in areas where visual impairment and blindness are most common. This is likely to be compounded by fear of the unknown as well as feelings of lack of worth. Too often, older women are likely to have poor self-esteem and low expectations. Indeed, there is considerable evidence that older women in particular do not perceive their sight as being as bad as a clinical examination would suggest. ${ }^{33}$ Thus, most try to carry on their routine tasks despite worsening disability including increased risk of falls and fractures ${ }^{34}$ as well as isolation and depression.

\section{CONCLUSION}

These findings highlight the broader reality that although women outlive men nearly everywhere in the world, they do not necessarily enjoy a good quality of life in their later years. This is often a result of disability caused by a range of chronic conditions, including but not limited to those affecting the eyes. As the population increases in many parts of the world, estimates suggest that by 2020 the number of people who are blind will have increased to around 76 million.

A number of international programmes have tried to tackle this growing burden. The Vision 2020 Initiative aims to eliminate all avoidable blindness by 2020 but pays little or no attention to issues of gender equity. Similar criticisms can be made of the most recent initiative from the WHO. Though its Universal Eye Health: A Global Action Plan for the Prevention of Blindness 2014-2019 ${ }^{35}$ did adopt the principles of universal health coverage (UHC) it paid almost no attention to goals, targets and indicators related to equality between women and men. Unless this 'gender blindness' is tackled in both research and service delivery, it seems likely that a large percentage of people who are still blind in 2020 will be women living in in the poorest parts of the world. ${ }^{36} 39$

Acknowledgements The authors would like to thank Karen Bonstein and Zahir Mirza for help with preparation of the document.

Contributors LD wrote the first draft of the paper. RDB reviewed this draft and added clinical content. LD is the corresponding author and both take responsibility for the content.

Funding The publication of this review was supported by the National Institute for Health Research (NIHR) Biomedical Research Centre based at Moorfields Eye Hospital NHS Foundation Trust and UCL Institute of Ophthalmology.

Disclaimer The views expressed are those of the author(s) and not necessarily those of the NHS, the NIHR or the Department of Health.

Competing interests None declared.

Patient consent Not required. 
Provenance and peer review Not commissioned; externally peer reviewed.

Data sharing statement No additional data are available.

Open access This is an open access article distributed in accordance with the Creative Commons Attribution Non Commercial (CC BY-NC 4.0) license, which permits others to distribute, remix, adapt, build upon this work non-commercially, and license their derivative works on different terms, provided the original work is properly cited, appropriate credit is given, any changes made indicated, and the use is non-commercial. See: http://creativecommons.org/ licenses/by-nc/4.0/.

\section{REFERENCES}

1. Ulldemolins AR, Lansingh VC, Valencia LG, et al. Social inequalities in blindness and visual impairment: a review of social determinants. Indian J Ophthalmol 2012;60:368-75.

2. Abou-Gareeb I, Lewallen S, Bassett K, et al. Gender and blindness: a meta-analysis of population-based prevalence surveys. Ophthalmic Epidemiol 2001;8:39-56.

3. Clayton JA, Davis AF. Sex/gender disparities and women's eye health. Curr Eye Res 2015;40:102-9.

4. SEVA. Gender and blindness: Initiatives to address inequity. A report by SEVA. 2012 http://www.iapb.org/sites/iapb.org/files/SEVA004Gender-Blindness-Report-5 5x8 5.pdf (accessed Nov 2016).

5. Zetterberg M. Age-related eye disease and gender. Maturitas 2016;83:19-26.

6. Anjum KM, Qureshi MB, Khan MA, et al. Cataract blindness and visual outcome of cataract surgery in a tribal area in Pakistan. $\mathrm{Br} J$ Ophthalmol 2006;90:135-8.

7. Courtright P, West SK. Contribution of sex-linked biology and gender roles to disparities with trachoma. Emerg Infect Dis 2004:10:2012-6.

8. Cromwell EA, Courtright P, King JD, et al. The excess burden of trachomatous trichiasis in women: a systematic review and metaanalysis. Trans R Soc Trop Med Hyg 2009;103:985-92.

9. Institute of Medicine (US). Committee on understanding the biology of sex and gender differences.. In: Wizemann TM, Pardue ML, Exploring the biological contributions to human health: does sex matter? Washington, DC: National Academy Press, 2001.

10. Marmot MG, Wilkinson RG. Social determinants of health. 2nd edn. Oxford: Oxford University Press, 2006.

11. Doyal L. Sex, gender, and health: the need for a new approach. BMJ 2001;323:1061-3.

12. Krieger N. Genders, sexes, and health: what are the connections-and why does it matter? Int J Epidemiol 2003;32:652-7.

13. Payne S. The health of men and women. Cambridge, UK; Malden, MA: Polity, 2006.

14. Eisner A. Sex, eyes, and vision: male/female distinctions in ophthalmic disorders. Curr Eye Res 2015;40:96-101.

15. Miljanović B, Dana R, Sullivan DA, et al. Impact of dry eye syndrome on vision-related quality of life. Am J Ophthalmol 2007:143:409-15.

16. Schaumberg DA, Uchino M, Christen WG, et al. Patient reported differences in dry eye disease between men and women: impact, management, and patient satisfaction. PLoS One 2013;8:e76121.

17. Vehof J, Kozareva D, Hysi PG, et al. Prevalence and risk factors of dry eye disease in a British female cohort. $\mathrm{Br} J$ Ophthalmol 2014;98:1712-7.

18. Cooper GS, Stroehla BC. The epidemiology of autoimmune diseases. Autoimmun Rev 2003;2:119-25.
19. Fairweather D, Frisancho-Kiss S, Rose NR. Sex differences in autoimmune disease from a pathological perspective. Am J Pathol 2008;173:600-9.

20. Wolfson EM, Fedewa L, Young SA. Trachoma: a women's health issue. Revised ed. New York, N.Y.: Global Alliance for Women's Health, 1999

21. Congdon N, West S, Vitale S, et al. Exposure to children and risk of active trachoma in Tanzanian women. Am J Epidemiol 1993;137:366-72.

22. Palmer SL, Winskell K, Patterson AE, et al. 'A living death': a qualitative assessment of quality of life among women with trichiasis in rural Niger. Int Health 2014;6:291-7.

23. Frick KD, Basilion EV, Hanson CL, et al. Estimating the burden and economic impact of trachomatous visual loss. Ophthalmic Epidemiol 2003;10:121-32.

24. Dhaliwal U, Nagpal G, Bhatia MS. Health-related quality of life in patients with trachomatous trichiasis or entropion. Ophthalmic Epidemiol 2006;13:59-66.

25. Hunt K, Adamson J, Galdas P. Gender and help-seeking: towards gender comparative studies. In: Kuhlmann E, Annandale E, eds. Palgrave handbook of gender and healthcare. Palgrave: Basingstoke, 2010.

26. Doyal L. Living with HIV and dying with AIDS diversity, inequality and human rights in the global pandemic. Farnham, Surrey, England: Ashgate, 2013:249.

27. Bastawrous A, Hennig BD. The global inverse care law: a distorted map of blindness. Br J Ophthalmol 2012;96:1357.2-8.

28. Joseph S, Ravilla T, Bassett K. Gender issues in a cataract surgical population in South India. Ophthalmic Epidemiol 2013;20:96-101.

29. Wolle MA, Cassard SD, Gower EW, et al. Impact of Trichiasis surgery on physical functioning in Ethiopian patients: STAR trial. Am J Ophthalmol 2011;151:850-7.

30. Geneau R, Lewallen S, Bronsard A, et al. The social and family dynamics behind the uptake of cataract surgery: findings from Kilimanjaro region, Tanzania. Br J Ophthalmol 2005;89:1399-402.

31. Mwende J, Bronsard A, Mosha M, et al. Delay in presentation to hospital for surgery for congenital and developmental cataract in Tanzania. Br J Ophthalmol 2005;89:1478-82.

32. Lane SD, Millar MI. The "hierarchy of resort' reexamined: status and class differentials as determinants of therapy for eye disease in the Egyptian delta. Urban Anthropology 1982;16:151-82.

33. Lane SD, Mikhail BI, Reizian A, et al. Sociocultural aspects of blindness in an Egyptian delta hamlet: visual impairment vs. visual disability. Med Anthropol 1993;15:245-60.

34. Ray CT, Wolf SL. Gender differences and the risk of falls in individuals with profound vision loss. J Visual Impair Blindness 2010;104:311-6.

35. WHO. Universal eye health: a global action plan 2014-2019. 2013 http://www.who.int/blindness/AP2014_19_English.pdf?ua=1

36. Ramke J, Zwi AB, Palagyi A, et al. Equity and blindness: closing evidence gaps to support universal eye health. Ophthalmic Epidemiol 2015;22:297-307.

37. Doyal L, Naidoo S. Why dentists should take a greater interest in sex and gender. Br Dent J 2010;209:335-7.

38. Gough B, Robertson S. Men, masculinities and health: critical perspectives, 2005.

39. Sen G, Östlin P, George A, et al. Unequal, unfair, ineffective and inefficient gender inequity in health: why it exists and how we can change it: a synthesis of the WHO Women and Gender Equity Knowledge Network final report. Antigonish, NS: National Collaborating Centre for Determinants of Health, 2008:34. 